\title{
Socio-economic inequality in the prevalence of violence against older adults - findings from India
}

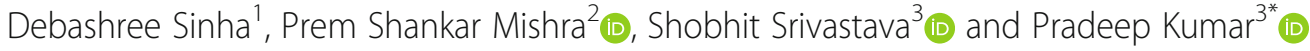

\begin{abstract}
Background: Violence against older adults is a well-recognised socio-psychological and public health problem. It is uncared-for, undiagnosed, and an untreated problem that is widespread across both developed and developing countries. The present paper aims to understand the extent of the socio-economic status related inequality in violence against older adults in India.

Methods: The study uses data from Building a Knowledge Base on Population Aging in India (BKPAl). Violence against older adults is the outcome variable for the study and is defined as older adults who faced any abuse or violence or neglect or disrespect by any person. Bivariate analysis and regression-based decomposition technique is used to understand the relative contribution of various socio-economic factors to violence against older adults ( $N=$ 9541).

Results: The prevalence of violence faced by older adults was $11.2 \%$. Older adults aged 80+ years [OR: 1.49; Cl: 1.14-1.93] and working [OR: 1.26; Cl: 1.02-1.56] had higher likelihood to face violence than their counterparts. On the other hand, older adults who were currently in union [OR: 0.79; Cl: 0.65-0.95], lived with children [OR: 0.53; Cl: 0.40-0.72] and who belonged to richer wealth quintile [OR: $0.35 ; \mathrm{Cl}: 0.24-0.51$ ] had lower likelihood to suffer from violence than their counterparts. The decomposition results revealed that poor older adults were more prone to violence (Concentration index: - 0.20). Household's wealth status was responsible for explaining $93.7 \%$ of the socioeconomic status related inequality whereas living arrangement of older adults explained $13.7 \%$ of the socioeconomic related inequality. Education and working status of older adults made a substantial contribution to the inequalities in reported violence, explaining 3.7\% and 3.3\% of the total inequality, respectively.

Conclusion: Though interpretation of the results requires a cautious understanding of the data used, the present study highlights some of the relevant issues faced by the country's older adults. With no or meagre income of their own, older adults belonging to the poorest wealth quintile have little or no bargaining power to secure a violent free environment for themselves. Therefore, special attention in terms of social and economic support should be given to the economically vulnerable older population.
\end{abstract}

Keywords: Violence, Older adults, Socio-economic inequality, India

\footnotetext{
* Correspondence: pradeepiips@yahoo.com

${ }^{3}$ Department of Mathematical Demography \& Statistics, International Institute for Population Sciences, Mumbai, Maharashtra 400088, India

Full list of author information is available at the end of the article
}

(c) The Author(s). 2021 Open Access This article is licensed under a Creative Commons Attribution 4.0 International License, which permits use, sharing, adaptation, distribution and reproduction in any medium or format, as long as you give appropriate credit to the original author(s) and the source, provide a link to the Creative Commons licence, and indicate if changes were made. The images or other third party material in this article are included in the article's Creative Commons licence, unless indicated otherwise in a credit line to the material. If material is not included in the article's Creative Commons licence and your intended use is not permitted by statutory regulation or exceeds the permitted use, you will need to obtain permission directly from the copyright holder. To view a copy of this licence, visit http://creativecommons.org/licenses/by/4.0/. The Creative Commons Public Domain Dedication waiver (http://creativecommons.org/publicdomain/zero/1.0/) applies to the data made available in this article, unless otherwise stated in a credit line to the data. 


\section{Background}

Globally in 2015, 900 million people were aged 60 years and above and it is speculated that there will be an increase of 2 billion older adults in 2050 [1]. Similarly. the population belonging to WHO's South-East Asia region is also ageing rapidly; for instance, the proportion of people aged 60 or above was $9.8 \%$ in 2017, and it is expected to increase to 13.7 and $20.3 \%$ by 2030 and by 2050, respectively [2]. India is no exception to the phenomenon of ageing. For example, according to the 2011 Census, India contributes $8.6 \%$ of the aged population and further, it is expected to increase to $20 \%$ in 2050 [3]. The increase in the aged population in every corner of the world has led to social and health problems and is accompanied by various forms of violence peretrated against the older adults.

The World Health Organization defines violence against older adults or elderly abuse as "a single or repeated act or lack of appropriate action, occurring within any relationship where there is an expectation of trust which causes harm or distress to an older person" [4]. In most of the cases older adults are abused by their own family members, spouses, friends, community members, and also by healthcare providers. There are multiple forms of violence and abuse that have been reported. These include physical, sexual, psychological, and emotional abuse; financial and material abuse; abandonment; neglect; and serious loss of dignity and respect [4-6].

Violence against older adults is a socio-psychological and public health problem that is well recognised across the world. It is largely undiagnosed, uncared-for, and an untreated problem that is widespread across both developed and developing countries [7-10]. It is reported that around one in six people aged 60 years and above experience some form of abuse or violence in the community or household level settings [4]. This has eventually led to devastating consequences like serious injuries, health, and long-term socio-economic and psychological problems experienced by the older adults [9, 11-14]. Moreover, abuse and violence against older adults is one of the most serious socio-psychological-health problem in low and middle-income countries [15], which is growing at an unprecedented rate; and can be seen in South Asian countries like India $[16,17]$. The lack of appropriate approach, neglect, and underreport of violence by older adults in these settings make it even more challenging. Further, violence is inversely associated with older adults' quality of life, and directly associated with morbidity and mortality rates $[5,13,18-20]$. The experience of abuse or any kind of violence faced by the older adults is also linked to their disability and functional limitation [18]. Again, several socio-economic determinants influence higher risk of violence faced by older adults' such as if the older person has low education, belongs to lowincome group, and poor social status $[3,9,12]$. Studies have found that there is a relationship between caste and violence $[18,21]$, education and violence [12] lowincome support and violence [22], unemployment and violence [23], poverty and violence against older adults [23]. Although there are other facets of certain risk factors that create an environment against older adults in physical and verbal abuse, however, it has not been extensively understood in the Indian scenario. Therefore, it becomes important to understand it thoroughly in the Indian context.

Though most of the studies found that a high incidence of violence against older adults exists in low socio-economic strata of the society, but it has not been frequently reported in many communities and therefore is highly underreported [3, 9, 12, 24]. Nevertheless, sometimes older adults feel the act of omission and commission in terms of violence or abuse, or mistreatment and they rarely report it. Until and unless it is an act of physical and verbal abuse or violence, they might not report it. The low coverage of such reporting is caused by several reasons such as inaccessible institutional support and lack of information, education, and communication [3, 12]. For understanding this, a systematic review presented and identified the major causes like the older adult faces nearly $11.6 \%$ psychological abuse, $6.8 \%$ financial abuse, 4.2 neglect, $2.6 \%$ physical violence, and $0.9 \%$ sexual abuse [15]. Similarly, a study in India showed that nearly $11 \%$ of older adults have experienced some form of violence after turning the age of 60 [12]. However, this significantly varies across sex and income groups. Existing literature emphasized the trends and patterns of older adults' violence in India that are consistently linked to their health and sociopsychological well-being $[9,11,25,26]$.

\section{Methods \\ Data}

The present study utilized data from the Building a Knowledge Base on Population Aging in India (BKPAI) which was a national level survey and was conducted in 2011, across seven states of India [27]. The study was cross-sectional in nature. The survey was sponsored by Tata Institute for social sciences (TISS), Institute for social and economic change (ISEC), Institute for economic growth (IEG) and UNFPA, New Delhi [27]. The survey gathered information on various socio-economic, demographic and health aspects of ageing among households with members aged 60 years and above [27]. Seven major regionally representative states were selected for the survey with the highest $60+$ year's population than the national average [27]. This survey was carried out on a representative sample in the northern, western, 
eastern, and southern parts of India following a random sampling process [27]. The questionnaires for each state were bilingual, with questions in both the primary language of the states and English [27].

The primary sampling unit (PSU) were villages for rural areas, and urban wards in urban areas [27]. The sample of 1280 elderly households was fixed for each state. Further details on the sampling procedure, the sample size is available in national and state reports of BKPAI, 2011 [27]. The actual sample size was 9852 older adults aged 60 years and above. For the current study, after removing the missing cases (311 cases) the effective sample size was 9541 older adults residing in seven states aged 60+ years were selected [27].

\section{Outcome variables}

The outcome variable was binary in nature. The question was asked to older adult that "Ever since you completed 60 years of age, have you faced any abuse or violence or neglect or disrespect by any person?" The response was coded as 0 "No" and 1 "Yes". Type of violence included were physical abuse, verbal abuse, economic abuse, showing disrespect and neglect [17].

\section{Predictor variables}

The predictor variables were included after doing extensive literature review:

1. Age in years $(60-69,70-79$ and $80+)[28,29]$.

2. Sex (men and women) [28, 29].

3. Education (none, below 5 years, $6-10$ years and $11+$ years) $[28,29]$.

4. Marital status (not in union and currently in union) [28-30].

5. Living arrangement (alone, with spouse, with children and others "includes other family members/relatives") [29].

6. Working status (no and yes) [28-31].

7. Contributed money to household expenditure (no income, yes and no) [29].

8. Wealth (poorest, poorer, middle, richer and richest) [28-33]. The wealth index was based on the following 30 assets and housing characteristics: household electrification; drinking water source; house ownership; type of toilet facility; type of house; ownership of a bank or post-office account; cooking fuel; and ownership of a mattress, a pressure cooker, a cot/bed, a table, a chair, an electric fan, a radio/transistor, a black and white television, a colour television, a mobile telephone, any landline phone, a sewing machine, a computer, internet facility; a refrigerator, a watch or clock, a bicycle, a motorcycle or scooter, an animal-drawn cart, a car, a water pump, a thresher and a tractor [28-31].
The range of index was from poorest to the richest i.e. ranging from lowest to the highest [28-34].

9. Religion (Hindu, Muslim, Sikh and others) [28-31].

10. Caste (Scheduled Caste (SC), Scheduled Tribe (ST), Other Backward Class, and Others) [28-32].

11. Place of residence (rural and urban) [28-31].

12. States (Himachal Pradesh, Punjab, West Bengal, Odisha, Maharashtra, Kerala and Tamil Nadu) [28-31].

\section{Research framework}

There are many theories such as social exchange theory, feminist theory, political-economic theory, psychopathology of the caregiver theory, role accumulation theory, situational theory, social learning theory, stratification theory, and symbolic interactionism theory that provides probable causes of older adults facing abuse and violence [35]. Similarly, other studies have proposed interventions to prevent elder abuse by lessons learned from child abuse and intimate partner violence [36]. However, after an extensive review of literature on violence faced by older adults, we have tried to develop a research framework that highlights the important role of socioeconomic characteristics as risk factors to violence experienced by older adults in India.

In the above Fig. 1, an older adult's household background characteristics like wealth quintile, religion, caste, place of residence, and state influence his individual, social and economic characteristics. Again, within the individual-level characteristics, an older adult's age and sex influence his/her social and economic characteristics. Further, an older adult's working status influences how much he can contribute to household expenditure. Finally, both individual and household level characteristics of an older adult affect his exposure to violence. The research framework also shows the link between various independent variables and the dependent variable. Thus, based on the above research framework and existing literature, this paper aims to understand the extent of socio-economic status related inequality in violence against older adults in the Indian society. The The effort is made to identify the most vulnerable population subgroup who suffers from different types of violence.

\section{Statistical analysis}

Descriptive statistics along with bivariate analysis were used to find the preliminary results [29]. Further, binary logistic regression analysis [37] has been done to fulfil the objective of the study. The results were presented in the form of adjusted odds ratio (OR) with a 95\% confidence interval (CI) [28].

The model is usually put into a more compact form as follows: 




Fig. 1 Research framework: risk factors to violence experiences by older adults

$$
\ln \left(\frac{P_{i}}{1-P_{i}}\right)=\beta_{0}+\beta_{1} x_{1}+\ldots+\beta_{M} x_{m-1},
$$

Where $\beta_{0}, \ldots ., \beta_{M}$ are regression coefficient indicating the relative effect of a particular explanatory variable on the outcome [29].

Moreover, wealth quintile was used as the key variable to measure the socio economic status of the particular household household [38]. A household wealth index was calculated in the survey by combining household amenities, assets and durables and characterizing households in a range varying from the poorest to the richest, corresponding to wealth quintiles ranging from the lowest to the highest [28].

The study used continuous wealth score for decomposition analysis and for the calculation of Concentration Index (CCI) [30, 31]. The study used wealth quintile which has been divided into five equal size of the population [30, 31].

\section{Concentration index}

Concentration index reveals the magnitude of inequality by estimating the area between the concentration curve and line of equality $[30,31]$, and calculated as two times the weighted covariance between the explanatory and fractional rank in the wealth distribution divided by variable mean [33].

The concentration index can be written as follows:

$$
C=\frac{2}{\mu} \operatorname{cov}\left(V_{i}, W_{i}\right)
$$

Where, $\mathrm{C}$ is the concentration index; $V_{i}$ is the outcome variable index; $W$ is the fractional rank of individual $\boldsymbol{i}$ in the distribution of socio-economic position; $\boldsymbol{\mu}$ is the mean of the outcome variable of the sample and cov denotes the covariance [39]. The index value lies between -1 to +1 [30, 31] .

Further, the study decomposed the concentration index to understand the relative contribution of various socioeconomic factors to violence faced by older adults [40]. To do this, the study used regression based decomposition technique, which was proposed by Wagstaff et al. [41].

\section{Results}

Socio-demographic profile of older adults and percentage of older adults who faced any violence by background characteristicsis are presented in Table 1. About three-fifth of older adults belonged to 60-69 years age group and nearly half of them were women. Only $6 \%$ of older adults had more than 11 years of education and same proportion of older adults were living alone. Around one-fourth of older adults were working and half of the older adults contributed money for household expenditure. Majority of older adults were Hindu and lived in rural areas. Further results show that older adults with $80+$ years of age (15.4\%), women (11.5\%) and those who had no education (13.6\%) reported more violence compared to their counterparts. Older adults with 
Table 1 Socio-economic profile of older adults and percentage of older adults who faced any violence by background characteristics in India

\begin{tabular}{|c|c|c|c|c|}
\hline Variables & Sample & Percentage & Any violence (\%) & $p$-value \\
\hline Age (years) & & & & 0.008 \\
\hline $60-69$ & 5890 & 61.8 & 10.7 & \\
\hline $70-79$ & 2612 & 27.4 & 10.7 & \\
\hline $80+$ & 1036 & 10.9 & 15.4 & \\
\hline Sex & & & & 0.029 \\
\hline Men & 4525 & 47.4 & 10.8 & \\
\hline Women & 5014 & 52.6 & 11.5 & \\
\hline Educational status & & & & 0.001 \\
\hline None & 4871 & 51.1 & 13.6 & \\
\hline Below 5 years & 1954 & 20.5 & 11.8 & \\
\hline 6 to 10 years & 2136 & 22.4 & 6.6 & \\
\hline $11+$ years & 578 & 6.1 & 6.0 & \\
\hline Marital status & & & & 0.001 \\
\hline Not in union & 3759 & 39.4 & 12.3 & \\
\hline Currently in union & 5780 & 60.6 & 10.5 & \\
\hline Living arrangement & & & & 0.001 \\
\hline Alone & 561 & 5.9 & 17.6 & \\
\hline With spouse & 1521 & 15.9 & 12.2 & \\
\hline With children & 6717 & 70.4 & 10.6 & \\
\hline Others & 740 & 7.8 & 9.6 & \\
\hline Working status & & & & 0.001 \\
\hline No & 7229 & 75.8 & 9.9 & \\
\hline Yes & 2310 & 24.2 & 15.2 & \\
\hline Contribute money for household expenditure & & & & 0.034 \\
\hline No income & 4110 & 43.1 & 10.7 & \\
\hline Yes & 5013 & 52.6 & 11.2 & \\
\hline No & 416 & 4.4 & 15.4 & \\
\hline Wealth quintile & & & & 0.001 \\
\hline Poorest & 2251 & 23.6 & 17.3 & \\
\hline Poorer & 2114 & 22.2 & 13.1 & \\
\hline Middle & 1970 & 20.7 & 8.4 & \\
\hline Richer & 1771 & 18.6 & 8.0 & \\
\hline Richest & 1433 & 15.0 & 6.4 & \\
\hline Religion & & & & 0.187 \\
\hline Hindu & 7570 & 79.4 & 11.1 & \\
\hline Muslim & 671 & 7.0 & 10.0 & \\
\hline Sikh & 898 & 9.4 & 12.4 & \\
\hline Others & 400 & 4.2 & 12.9 & \\
\hline Caste & & & & 0.045 \\
\hline Scheduled Caste & 1979 & 20.7 & 12.0 & \\
\hline Scheduled Tribe & 531 & 5.6 & 14.0 & \\
\hline Other Backward Class & 3507 & 36.8 & 7.9 & \\
\hline Others & 3522 & 36.9 & 13.5 & \\
\hline
\end{tabular}


Table 1 Socio-economic profile of older adults and percentage of older adults who faced any violence by background characteristics in India (Continued)

\begin{tabular}{|c|c|c|c|c|}
\hline Variables & Sample & Percentage & Any violence (\%) & $p$-value \\
\hline Place of residence & & & & 0.001 \\
\hline Rural & 7042 & 73.8 & 12.2 & \\
\hline Urban & 2497 & 26.2 & 8.3 & \\
\hline State & & & & 0.001 \\
\hline Himachal Pradesh & 1470 & 15.4 & 11.5 & \\
\hline Punjab & 1351 & 14.2 & 10.4 & \\
\hline West Bengal & 1127 & 11.8 & 7.5 & \\
\hline Orissa & 1453 & 15.2 & 9.2 & \\
\hline Maharashtra & 1380 & 14.5 & 34.3 & \\
\hline Kerala & 1356 & 14.2 & 2.9 & \\
\hline Tamil Nadu & 1403 & 14.7 & 1.9 & \\
\hline Total & 9539 & 100 & 11.2 & \\
\hline
\end{tabular}

higher education and currently in union faced less any violence in the household. Older adults who lived alone $(17.6 \%)$ and working (15.2\%) reported more violence than those who lived with others and not working respectively. Older adults those who did not contribute money for household expenditure (15.4\%) faced more any violence compared to therest of the categories. There was a negative association between wealth quintile and reporting of violence by older adults. A higher proportion of older adults belonged to Scheduled Tribe and lived in rural areas reported more violence than other caste categories and those who lived in urban areas. The highest percentage of violence was reported in Maharashtra (34.3\%) followed by Himachal Pradesh (11.5\%).

Results from logistic regression estimates for violence among older adults were presented in Table 2. The likelihood of violence was significantly higher among older adults with age $80+$ years (OR, 1.49; CI: $1.14-1.93)$ compared to 60-69 years age group. Moreover, older adults currently in union (OR, 0.79; CI: 0.65-0.95) were less likely to face violence than those who were not in union. Older adults those who were working (OR, 1.26; CI: 1.02-1.56) reported significantly higher odds of violence compared to those who were not working. The likelihood of violence was higher among older adults those who did not contribute money for household expenditure (OR, 1.25; CI: 1.05-1.86) than reference category. The odds of violence was higher in Maharashtra (OR, 3.43 CI: 2.62-4.75) however it was lower in West Bengal (OR, 0.50; CI: 0.34-0.72), Orissa (OR, 0.56; CI: 0.390.82), Kerala (OR, 0.28; CI: 0.18-0.44) and Tamil Nadu (OR, 0.13; CI: 0.08-0.22) compared to Himachal Pradesh.

Figure 2 depicts the concentration curve for violence reported by older adults in India. Since the concentration curve lies above the line of equality it implies that violence among older adults is concentrated among the poor. If the curve was formed below the line of equality then the inequality would concentrate towards rich and vice-versa. Moreover, more the area between line of equality and curve higher the inequality. India was having inequality of -0.20 which depicts that violence was concentrated more among poor older adults.

Estimates of decomposition analysis for the contribution of various explanatory variables to violence among older adults are presented in Table 3. The positive scores of concentration index denotes that violence among older adults concentrated among rich older adults for that particular predictor and vice-versa. Older adults aged 70-79years, women, living with spouse, working, those contributing money for household expenditure, belonging poorer wealth quintile, and to $\mathrm{SC} /$ ST categories and living in urban areas concentrated more among disadvantaged population in terms of reported violence. On the other hand, having secondary or higher education, currently in union, living with children, and belonging to Muslim or Sikh religion inclined to concentrate among the better off. Household's wealth status, living arrangement, education, and working status of older adults were the major contributors to the inequalities. Household's wealth status was responsible for explaining $93.7 \%$ of the SES-related inequality whereas living arrangement of older adults explained 13.7\% SESrelated inequality. Education and working status of older adults made a substantial contribution to the inequalities in reported violence, explaining 3.7 and $3.3 \%$ of the total inequality, respectively.

\section{Discussion}

Using the BKPAI data of 2011, the present paper tried to understand the socio-economic inequality for violence among 9541 older adults residing in the Indian states of 
Table 2 Logistic regression estimates for violence among older adults by background characteristics in India

\begin{tabular}{ll}
\hline Background characteristics & Odds Ratio $(95 \% \mathrm{Cl})$ \\
\hline Age (years) & Ref. \\
$60-69$ & $0.97(0.78,1.19)$ \\
$70-79$ & $1.49^{*}(1.14,1.93)$ \\
$80+$ & \\
Sex & Ref. \\
Men & $0.96(0.78,1.19)$ \\
Women & \\
Educational status & Ref. \\
None & $1.08(0.89,1.32)$ \\
Below 5 years & $0.79^{*}(0.63,1)$ \\
6 to 10 years & $0.60^{*}(0.39,0.9)$ \\
$11+$ years & \\
Marital status & Ref. \\
Not in union & $0.79^{*}(0.65,0.95)$ \\
Currently in union & \\
Living arrangement & Ref. \\
Alone & $0.69^{*}(0.48,0.98)$ \\
With spouse & $0.53^{*}(0.4,0.72)$ \\
With children & $0.44^{*}(0.3,0.66)$ \\
Others & \\
Working status & Ref. \\
No & $1.26^{*}(1.02,1.56)$ \\
Yes & \\
\hline
\end{tabular}

Contribute money for household expenditure No income Ref. $\begin{array}{ll}\text { Yes } & 0.92(0.74,1.16)\end{array}$

No $1.25 *(1.05,1.86)$

Wealth quintile

Poorest

Ref.

Poorer

$0.63^{*}(0.5,0.79)$

Middle

$0.43^{*}(0.32,0.58)$

Richer

$0.39 *(0.29,0.53)$

Richest

$0.35^{*}(0.24,0.51)$

Religion

Hindu

Ref.

Muslim

$1.08(0.75,1.55)$

Sikh

$1.51 *(1.04,2.18)$

Others

$1.09(0.72,1.66)$

\section{Caste}

Scheduled Caste

Ref.

Scheduled Tribe

Other Backward Class
Table 2 Logistic regression estimates for violence among older adults by background characteristics in India (Continued)

\begin{tabular}{ll}
\hline Background characteristics & Odds Ratio $\mathbf{( 9 5 \% ~ C l )}$ \\
\hline Place of residence & Ref. \\
Rural & $0.94(0.78,1.14)$ \\
Urban & \\
State & Ref. \\
Himachal Pradesh & $0.82(0.56,1.2)$ \\
Punjab & $0.50^{*}(0.34,0.72)$ \\
West Bengal & $0.56^{*}(0.39,0.82)$ \\
Orissa & $3.53^{*}(2.62,4.75)$ \\
Maharashtra & $0.28^{*}(0.18,0.44)$ \\
Kerala & $0.13^{*}(0.08,0.22)$ \\
Tamil Nadu & \\
${ }^{*} p<0.05 ; C l$ Confidence Interval, Ref Reference category
\end{tabular}

Himachal Pradesh, Punjab, West Bengal, Odisha, Maharashtra, Kerala and Tamil Nadu. The key highlights of the present paper are as follows: First, the prevalence of violence faced by older adults is $11.2 \%$. However, there is a considerable state-wise variation in the prevalence of violence. For example, while older adults in Tamil Nadu experience the least violence (1.9\%), older adults in Maharashtra face the most (34.3\%). Second, while the positive significant determinants of experiencing violence among the older adults are age and work status, the negative significant determinants are educational and marital status, living arrangement, and wealth quintile. Third, there exist clear evidence of socio-economic inequality in experiencing violence and the household's wealth status contributed to the maximum; consequently, older adults belonging to the poorer sections of the society are more susceptible to violence. The results are in consistent with the proposed research framework where different socio-economic risk factors influence an older adult's exposure to violence.

Elder abuse is prevalent worldwide but given the rapid ageing of population in Asia, the number of abused elders in Asia are also expected to rise [42]. For instance, a study in Nepal showed that the prevalence of elder abuse was 50.3\% [43]. Again, in Bangladesh 27.2\% of older adults faced elder abuse [44]. The situation in India is even more alarming. One-eighth of the world's older adult lives in India. With falling income and health, breaking of the joint family and change in social attitudes, the older adults are the most vulnerable subpopulation of the country. Coupled with this, abuse faced by older adult's is becoming more and more prevalent in India [3, 17, 45]. The study results indicated that the overall prevalence of any violence faced by older adults is $11.2 \%$. Similar studies that have investigated the prevalence of elder abuse in the Indian context by using 


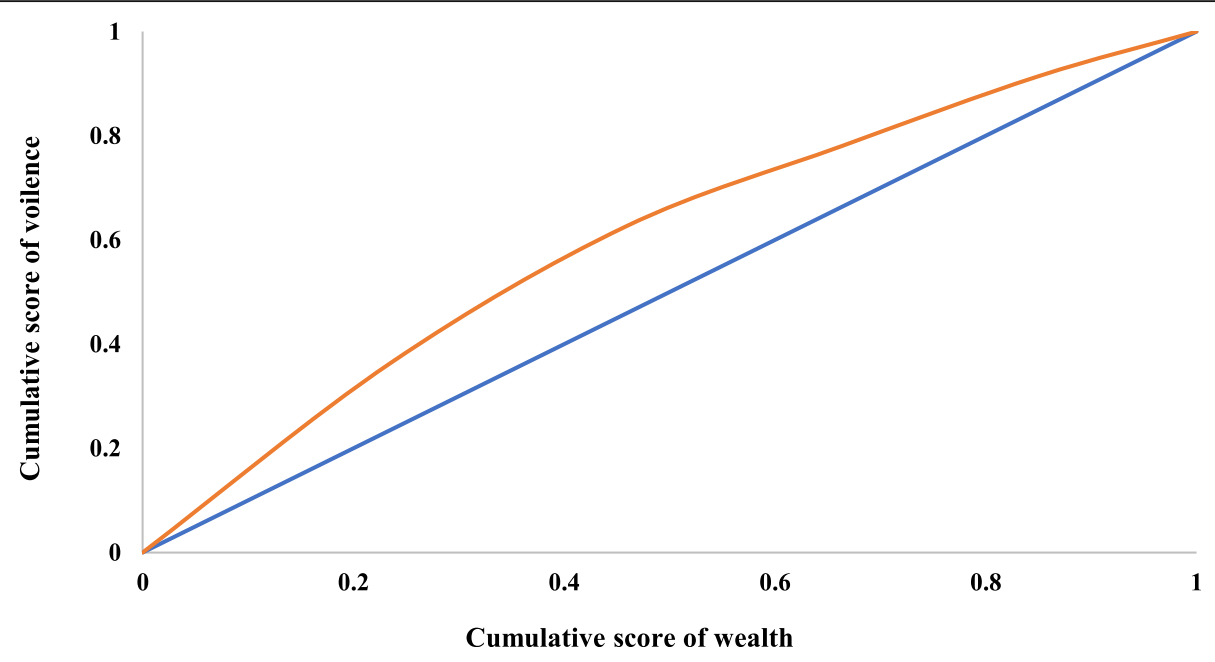

Fig. 2 Concentration curve for violence among older adults in India

the BKPAI data reports that $10-11 \%$ of older adults face abuse $[12,46]$. Further, among the seven states included in the current data older adults in Maharashtra face the maximum abuse and the minimum is faced by older adults in Tamil Nadu. The finding is consistent with existing literature [46, 47]. Various other community based cross-sectional studies on elder abuse in India show that overall abuse rate can lie in the range from 9.36 to $25.6 \%$ [3, 48]. To better understand the situation of elder abuse in India, regular surveys are conducted by HelpAge India. According to the recent survey, it was reported that nearly $25 \%$ of older adults experience abuse in the country [49].

Our finding that the likelihood of experiencing violence increases with age contradicts with studies [5052]. However, excerpts from focus group discussion on reasons of abuse among older adults due to age revealed that since the older adults are not young and do not belong to vibrant young culture, it is easy to being disrespected [53]. Education is found to be a significant negative predictor of experience of violence among older adults and is in line with other studies $[11,50,51,54$, 55]. However, higher educational attainment may also affect the level of openness on abuse among the older adults and therefore, they might be unwilling to share information on sensitive topics like abuse to maintain a family façade [12]. A popular believe is that, those who are economically independent have lesser odds of experiencing violence [56]. Yet, our results indicated otherwise - older adults with working status experience higher odds of violence. The possible explanations for our study finding may be because the income earned is forcibly taken by household members suggesting the presence of economic violence. Further, those who do not contribute money for household expenses are more likely to experience violence because they are economically dependent on their children [57]. Therefore, our study results indicate that for older adults being employed (i.e., economically independent) as well as not contributing to household expenses (i.e., economically dependent), both act as risk factors to experience violence.

Our decomposition results indicate that there exists economic inequality in reporting of violence by older adults. A study by Naughton et al., 2012 in Ireland showed that individuals with a low-income had a doubled risk of being victims of abuse of any kind [58]. Likewise, low income was associated with neglect, but not when other forms of abuse was considered [59]. In Iran, Hosseinkhani, Zahra Khodamoradi \& Sheikh, 2019 found that older adults belonging to lower socioeconomic status were majorly at the risk of abuse [22]. The World Health Organization (WHO) and International Network for the Prevention of Elder Abuse (INPEA) in their study Missing Voices gathered the views of older persons on elder abuse and showed that poverty and inequality are reasons for elder abuse [60]. Keskinoglu et al., 2007 tried to explain the factors such as living with many family members and with low family income that cause violence towards older adults with low income [61]. Further, the rates of abuse among older adults are highest in families where income levels for the older adult and for the abuser/caregiver are extremely low [62] and, there is low coverage of social security for older adults that tends to increase the burden on their care givers [12].

Traditional Indian values have always perceived old age as a stage of wisdom, maturity, prestige, and power, with respect given to older adults, especially to the oldest male [23]. India also represents an orthodox and patriarchal society where older adults have been taken 
Table 3 Estimates of decomposition analysis for contribution of various explanatory variables for violence among older adults in India

\begin{tabular}{|c|c|c|c|c|c|}
\hline Background characteristics & Coefficient & Elasticity & $\mathrm{CCl}$ & Absolute contribution & $\%$ Contribution \\
\hline \multicolumn{6}{|l|}{ Age (years) } \\
\hline \multicolumn{6}{|l|}{$60-69$} \\
\hline $70-79$ & 0.06 & -0.001 & -0.014 & 0.000 & -0.1 \\
\hline $80+$ & $0.51^{*}$ & 0.004 & 0.018 & 0.000 & -0.3 \\
\hline \multicolumn{6}{|l|}{ Sex } \\
\hline \multicolumn{6}{|l|}{ Men } \\
\hline Women & -0.05 & -0.001 & -0.033 & 0.000 & -0.2 \\
\hline \multicolumn{6}{|l|}{ Educational status } \\
\hline \multicolumn{6}{|l|}{ None } \\
\hline Below 5 years & 0.08 & 0.003 & 0.002 & 0.000 & 0.0 \\
\hline 6 to 10 years & $-0.23^{*}$ & -0.003 & 0.260 & -0.001 & 3.8 \\
\hline $11+$ years & -0.52 & 0.000 & 0.613 & 0.000 & 0.0 \\
\hline
\end{tabular}

\section{Marital status}

Not in union

Currently in union

$-0.24^{*}$

$-0.009$

0.040

0.000

1.7

Living arrangement

Alone

With spouse

$-0.37^{*} \quad-0.005$

$-0.197$

0.001

$-4.7$

With children

$-0.63^{*}$

$-0.038$

0.089

$-0.003$

16.3

Others

$-0.81^{*}$

$-0.005$

0.092

0.000

Working status

No

Yes

$0.23^{*}$

0.004

$-0.174$

$-0.001$

3.3

Contribute money for household expenditure

No income

Yes

$-0.12$

$-0.003$

$-0.006$

0.000

$-0.1$

No

$0.16^{*}$

0.001

$-0.054$

0.000

0.3

0.2

Wealth quintile

Poorest

Poorer

$\begin{array}{ll}-0.38^{*} & -0.012\end{array}$

$-0.338$

0.004

$-19.5$

Middle

$-0.73^{*}$

$-0.018$

0.139

$-0.003$

12.0

Richer

$-0.91^{*}$

$-0.017$

0.523

$-0.009$

42.7

Richest

$-1.03^{*}$

$-0.016$

0.760

$-0.012$

58.5

Religion

Hindu

Muslim

0.03

0.001

0.146

0.000

$-0.7$

Sikh

$0.37^{*}$

0.004

0.311

0.001

$-6.0$

Others

0.06

0.000

0.296

0.000

0.0

Caste

Scheduled Caste

Scheduled Tribe

0.01

$-0.001$

$-0.444$

0.000

$-2.1$

Other Backward Class

$-0.001$

$-0.029$

0.000

0.30 *

0.012

0.219

0.003

$-0.1$

$-12.6$ 
Table 3 Estimates of decomposition analysis for contribution of various explanatory variables for violence among older adults in India (Continued)

\begin{tabular}{|c|c|c|c|c|c|c|}
\hline Background characteristics & Coefficient & Elasticity & $\mathrm{CCl}$ & Absolute contribution & $\%$ Contribution & \\
\hline \multicolumn{7}{|l|}{ Place of residence } \\
\hline \multicolumn{7}{|l|}{ Rural } \\
\hline Urban & -0.07 & -0.001 & 0.247 & 0.000 & 1.2 & 1.2 \\
\hline \multicolumn{7}{|l|}{ State } \\
\hline \multicolumn{7}{|l|}{ Himachal Pradesh } \\
\hline Punjab & -0.05 & -0.003 & 0.331 & -0.001 & 4.8 & \\
\hline West Bengal & $-0.50^{*}$ & -0.007 & -0.163 & 0.001 & -5.5 & \\
\hline Orissa & $-0.59^{*}$ & -0.008 & -0.368 & 0.003 & -14.2 & \\
\hline Maharashtra & $1.29^{*}$ & 0.031 & -0.125 & -0.004 & 18.6 & \\
\hline Kerala & $-1.06^{*}$ & -0.010 & 0.349 & -0.003 & 16.8 & \\
\hline Tamil Nadu & $-2.04^{*}$ & -0.015 & -0.222 & 0.003 & -16.0 & 4.5 \\
\hline Total & & & & & 100.0 & 100.0 \\
\hline Calculated Cl & & & & -0.021 & & \\
\hline Actual Cl & & & & -0.198 & & \\
\hline Residual & & & & -0.177 & & \\
\hline
\end{tabular}

CCI Concentration index; *if $p<0.05$; \%: percentage

care of by their sons and daughters-in-law. Given the low coverage of social security for older adults in India, it tends to increase burden on families who support older adults [12]. A recent verbatim from focus group discussions reveal that older adults are now considered as burden in the society [45]. Further, of all the forms of violence, negligence, abandonment, and financial abuse are the most common form of violence faced by older adults in India [21, 26, 63]. However, most of the time these go underreported [24] since it is usually penetrated by family members in Indian society [24-26]. Additionally, along with physical disability, poor physical and mental health, the other associated risk factors of violence comprise of poor socio-economic condition of the older adults $[3,9,64]$. Literature found that older adults who belong to lower economic strata, lower caste group and having low education are more prone to abuse and violence compare to their counterpart [3, 12, 21, 57]. Therefore, violence faced by older adults has created social and health vulnerability $[5,20,24]$.

Our study is not devoid of limitations. One of them is that the analysis is based on cross-sectional data that limited our scope to do cause-effect analysis. Second, one must be cautious while interpretating the results of the present study since the data used for analysis covers only the states of Himachal Pradesh, Punjab, West Bengal, Odisha, Maharashtra, Kerala and Tamil Nadu, and not all the states of the country. Third, the outcome variable did not measure the time reference like whether the respondent experienced violence 6 months back or a year back. Time reference is important to avoid recall bias or to get the accurate information. Fourth, since the question on elder abuse is sensitive in nature it depends on how the older adults have responded to it; various factors like whether the response was given in presence of others or not, whether he was stressed or not might affect the response given. Finally, since the data is a decade old so it cannot be generalized now.

\section{Conclusion}

The results indicate that violence among older adults is prevalent in the Indian society and therefore, an understanding of its determinants is valuable for policy makers to improve the services towards the older adults of the country. The existence of economic inequality in reporting of violence shows the miserable conditions of the older adults belonging to the poorest wealth quintile. With no or meagre income of their own, they have little or no bargaining power to secure a violent free environment for themselves. Social and economic support should be given to these older adults to live a dignified life. Finally, keeping in mind, the changing pattern of Indian culture and values, efforts should be made to make individuals across all age group respect, honour and care for the older adults.

\section{Abbreviations}

BKPAl: Building a Knowledge Base on Population Aging in India; ISEC: Institute for social and economic change; TISS: Tata Institute for social sciences; IEG: Institute for economic growth; PSU: Primary Sampling Unit; SC: Scheduled Caste; ST: Scheduled Tribe; OR: Odds Ratio; CCl: Concentration Index; SES: Socio Economic Status; WHO: World Health Organization; INPEA: International Network for the Prevention of Elder Abuse 


\section{Acknowledgements}

Not applicable.

\section{Authors' contributions}

Conception and design of the study: DS, SS, PSM and PK; Analysis and/or interpretation of data: PK and SS; Drafting the manuscript: PSM, and DS; Reading and approving the manuscript: DS, PSM, SS and PK. All authors have read and approved the manuscript.

\section{Funding}

We declare that we did not receive any funding for this work.

\section{Availability of data and materials}

We have provided details of the data in the methodology section. The BKPAI data can be obtained from the ISEC Bangalore. The report and the survey tools are also available on the website: https://india.unfpa.org/sites/default/ files/pub-pdf/AgeingReport_2012_F.pdf

\section{Declarations}

\section{Ethics approval and consent to participate}

The study is based on secondary data, which is in public domain and available on request. Therefore, ethical approval and consent to participate are not required.

\section{Consent for publication}

Not applicable.

\section{Competing interests}

Authors declare that they do not have any competing interest.

\section{Author details}

'Department of Development Studies, International Institute for Population Sciences, Mumbai, Maharashtra 400088, India. ${ }^{2}$ Population Research Centre, Institute for Social and Economic Change, Bengaluru, Karnataka 560072, India. ${ }^{3}$ Department of Mathematical Demography \& Statistics, International Institute for Population Sciences, Mumbai, Maharashtra 400088, India.

\section{Received: 3 September 2020 Accepted: 19 April 2021}

Published online: 20 May 2021

\section{References}

1. United Nations, Department of Economic and Social Affairs PD. World Population Prospects The 2015 Revision, Key Findings and Advance Tables. Work Pap No ESA/P/WP241.

2. World report on Ageing And HeAltH, www.who.int (2015, Accessed 24 Dec 2019).

3. Sembiah S, Dasgupta A, Taklikar CS, et al. Elder abuse and its predictors: a cross-sectional study in a rural area of West Bengal, Eastern part of India. Psychogeriatrics. 2020;20:636-44.

4. WHO. Abuse of the elderly. 2020

5. Perel-Levin S. Abuse, neglect and violence against older persons. UNDESA Expert Gr Meet Older Pers Emerg Cris New York; 2019. p. 1-10.

6. WHO. Global status prevention violence report on 2014. 2014. Epub ahead of print 2014;21(1):87-108. https://doi.org/10.1080/14768320500230185.

7. Mosqueda L, Burnight K, Gironda M. Intervention the Abuse intervention model: A pragmatic approach to. J Am Geriatr Soc. 2016;64(9):1879-83. https://doi.org/10.1111/jgs.14266.

8. Ho CSH, Wong SY, Chiu MM, Ho RC. Global prevalence of elder abuse: A meta-analysis and meta-regression. East Asian Arch Psychiatr. 2017;27(2):4355.

9. Evandrou M, Falkingham JC, Qin M, et al. Elder abuse as a risk factor for psychological distress among older adults in India: A cross-sectional study. BMJ Open. 2017;7:e017152. Epub ahead of print 2017. https://doi.org/10.113 6/bmjopen-2017-017152

10. WHO. World report and ageing on health. 2015.

11. Dong X, Beck T, Simon MA. The associations of gender, depression and elder mistreatment in a community- dwelling Chinese population : The modifying effect of social support. Arch Gerontol Geriatr. 2010:50:202-8. https://doi.org/10.1016/j.archger.2009.03.011.
12. Skirbekk V, James KS. Abuse against elderly in India - the role of education. BMC Public Health. 2014;14:1-8.

13. Shahi $P$, Julka D. Prevalence of Abuse in elders with psychiatric morbidity and its Sociodemographic association study design. Cureus. 2020;12:1-7.

14. Dong X, Simon MA, Mba RO, et al. Depression and elder Abuse and neglect among a community-dwelling Chinese elderly population. J Elder Abuse Negl. 2008;20(1):25-41. https://doi.org/10.1300/J084v20n01_02.

15. Yon Y, Mikton CR, Gassoumis ZD, Wilber KH. Elder abuse prevalence in community settings: a systematic review and meta-analysis. Lancet Glob Health. 2017:5(2):e147-56. https://doi.org/10.1016/S2214-109X(17)30006-2.

16. Talpur A, Ryan T, Ali PA, et al. Elder mistreatment in south Asian communities : a review of the literature. J Adult Protect. 2018;20(5/6):193206. https://doi.org/10.1108/JAP-06-2018-0011.

17. Chaurasia H, Srivastava S. Abuse, neglect, and disrespect against older adults in India. J Popul Ageing. 2020. Epub ahead of print 18 March 2020. https:// doi.org/10.1007/s12062-020-09270-x.

18. Sathya T, Premkumar R. Association of functional limitations and disability with elder abuse in India: a cross-sectional study. BMC Geriatr. 2020;20:220

19. Young LM. Elder physical abuse. Clin Geriatr Med. 2014;30(4):761-8. https:// doi.org/10.1016/j.cger.2014.08.005.

20. Pillemer K, Burnes D, Riffin C, et al. Elder abuse: global situation, risk factors and prevention strategies. Gerontologist. 2016;56:194-205.

21. Universitesi $S$, Informa $R$, Number WR, et al. Issues of elder care and elder Abuse in the Indian context. J Aging Soc Policy. 2008;15:37-41.

22. Hosseinkhani Z, Khodamoradi F, Sheikh S. Socioeconomic inequality of elder abuse in Qazvin, Iran. Soc Heal Behav. 2019:47-51.

23. Kumar SV. Economic security for the elderly in India : an overview. J Aging Soc Policy. 2003;15(2-3):45-65. https://doi.org/10.1300/J031v15n02_04.

24. Soneja S. Elder abuse in india: Country Report for World Health Organization. New Delhi: Help India C-14, Qutab Institutional Area; 2001.

25. Arulmohi M, Vinayagamoorthy V. Physical violence against doctors: A content analysis from online Indian newspapers. Indian J Community Med. 2017:42:147-50.

26. Sooryanarayana $\mathrm{R}$, Choo WY, Hairi NN. A review on the prevalence and measurement of elder Abuse in the community. Trauma Violence Abuse. 2013;14(4):316-25. https://doi.org/10.1177/1524838013495963.

27. UNFPA. Report on the Status of Elderly in Select States of India, 2011. 2011.

28. Srivastava S, Kumar P, Sinha D, et al. Oral health matters-tooth problem and its treatment-seeking behaviour among older adults in India; 2020. Epub ahead of print 17 August 2020. https://doi.org/10.21203/rs.3.rs-55569/v1.

29. Srivastava S, Chauhan S, Muhammad T, et al. Older adults' psychological and subjective well-being as a function of household decision making role: Evidence from cross-sectional survey in India. Clin Epidemiol Glob Health 2021;10:100676. Epub ahead of print 1 April 2021. DOI: https://doi.org/10.1 016/j.cegh.2020.100676.

30. Patel $R$, Srivastava $S$, Kumar $P$, et al. Socio-economic inequality in functional disability and impairments with focus on instrumental activity of daily living: a study on older adults in india. 2021. Epub ahead of print 16 February 2021. https://doi.org/10.21203/rs.3.rs-234686/v1.

31. Srivastava S, Purkayastha N, Chaurasia H, Muhammad T. Socioeconomic inequality in psychological distress among older adults in India: a decomposition analysis. BMC Psychiatry. 2021;21(1):179. https://doi.org/10.11 86/s12888-021-03192-4

32. Srivastava S, Kumar S. Does socio-economic inequality exist in micronutrients supplementation among children aged 6-59 months in India? Evidence from National Family Health Survey 2005-06 and 2015-16. BMC Public Health. 2021;21:1-2. Epub ahead of print December 2021. https://doi. org/10.1186/s12889-021-10601-6.

33. Singh SK, Srivastava S, Chauhan S. Inequality in child undernutrition among urban population in India: a decomposition analysis. BMC Public Health. 2020:20(1):1852. https://doi.org/10.1186/s12889-020-09864-2.

34. Kumar P, Patel R, Chauhan S, Srivastava S, Khare A, Kumar Patel K. Does socio-economic inequality in infant mortality still exists in India? An analysis based on National Family Health Survey 2005-06 and 2015-16. Clin Epidemiol Glob Health. 2021;9:116-22. https://doi.org/10.1016/j.cegh.2020. 07.010 .

35. Abolfathi Momtaz $Y$, Hamid TA, Ibrahim R. Theories and measures of elder abuse. Psychogeriatrics. 2013;13(3):182-8. https://doi.org/10.1111/psyg.12 009.

36. Teresi JA, Burnes D, Elizabeth A, et al. State of the science on prevention of elder abuse and lessons learned from child abuse and domestic violence 
prevention : toward a conceptual framework for research. J Elder Abuse Negl. 2016;28(4-5):263-300. https://doi.org/10.1080/08946566.2016.1240053.

37. Osborne J, King JE. Binary logistic regression. In: Best Practices in Quantitative Methods. SAGE Publications, Inc.; 2008. p. 358-84. https://doi. org/10.4135/9781412995627

38. Srivastava S, Kumar S. Does socio-economic inequality exist in micronutrients supplementation among children aged 6-59 months in India ? Evidence from National Family Health. BMC Public Health. 2021;21:1-12.

39. O'donnell O, Van Doorslaer $E$, Wagstaff $A$, et al. Analyzing health equity using household survey data: a guide to techniques and their implementation: The World Bank; 2007. https://doi.org/10.1596/978-0-82136933-3.

40. Srivastava S, Chauhan S, Patel R. Socio-economic inequalities in the prevalence of poor self-rated health among older adults in India from 2004 to 2014: a decomposition analysis. Ageing Int. 2020. Epub ahead of print 29 June 2020. https://doi.org/10.1007/s12126-020-09385-8

41. Wagstaff $A$, Paci $P$, van Doorslaer $E$. On the measurement of inequalities in health. Soc Sci Med. 1991;33(5):545-57. https://doi.org/10.1016/0277-9536(91 )90212-U.

42. Yan E, Chan EK, Tiwari A. A systematic review of prevalence and risk factors for elder Abuse in Asia. Trauma Violence Abuse. 2014;16:199-219.

43. Chalise HN, Paudel BR. Elderly Abuse among community-living older adults of least developed country-Nepal. Arch Phys Rehabil Med. 2020;1:1-8.

44. Rahman KMM, Tareque MI, Munsur AM, et al. Elderly Abuse : causes and determinants in rural Naogan District of Bangladesh. J Popul Soc Stud. 2010; 19:25-36

45. Rashmi A, Sequeira L, Kumar PS, Rashmi A. Elder Abuse in Indian setting-A misconception or a reality- A deductive analysis. Indian J Public Health Res Dev. 2020;11(1):31-4. https://doi.org/10.37506/v11/i1/2020/ijphrd/193779.

46. Seth N, Yadav A, Adichwal NK, Kamble SB. Elder abuse and its association with socio-demographic variables in India. Clin Epidemiol Glob Health. 2019; 7(2):188-91. https://doi.org/10.1016/j.cegh.2018.05.002.

47. Chaurasia H, Sarode S. Exploring potential linkages between social support, retirement and subjective wellbeing among older indians: does it a challenge to policy makers? Ageing Int. 2018;43:207-36.

48. Saikia AM, Mahanta N, Mahanta A, Deka AJ, Kakati A. Prevalence and risk factors of abuse among community dwelling elderly of guwahati city, assam. Indian J Community Med. 2015;40(4):279-81. https://doi.org/10.4103/ 0970-0218.164406

49. HelpAge India. Annual report 2018-19 EMPOWERING ELDERS transforming lives. 2018.

50. Dong $X$, Simon MA, Gorbien M. Elder Abuse and neglect in an urban Chinese population elder Abuse and neglect in an urban Chinese population. J Elder Abus Negl. 2007;19(3-4):79-96. https://doi.org/10.1300/ J084v19n03_05.

51. Lai DW. Abuse and neglect experienced by aging Chinese in Canada Abuse and neglect experienced by aging Chinese in Canada. J Elder Abuse Negl. 2011;23(4):326-47. https://doi.org/10.1080/08946566.2011.584047.

52. Ruelas-gonzález MG, Duarte-gómez MB, Flores-hernández S, et al. Prevalence and factors associated with violence and abuse of older adults in Mexico 's 2012 National Health and nutrition survey. Int J Equity Health 2016:15:1-9.

53. Ploeg J, Lynne L, Walsh CA. What is " elder Abuse "? Voices from the margin : the views of underrepresented Canadian older adults. J Elder Abuse Negl. 2013;25(5):396-424. https://doi.org/10.1080/08946566.2013.780956.

54. Ghodousi A, Maghsoodloo S, Mohsen S, et al. Original article forensic aspect of elder abuse: risk factors and characteristics. J Res Med Sci. 2011;16(12): 1598-604.

55. Fraga S, Lindert J, Barros H, Torres-González F, loannidi-Kapolou E Melchiorre MG, et al. Elder abuse and socioeconomic inequalities : A multilevel study in 7 European countries. Prev Med. 2014;61:42-7. https:// doi.org/10.1016/j.ypmed.2014.01.008.

56. Yalç M, Kara F. Prevalence of violence against older adults and associated factors in Çanakkale, Turkey: A cross-sectional study. Geriatr Gerontol Int 2019:20:66-71.

57. Chokkanathan S, Lee AEY. Elder mistreatment in urban India : A community based study elder mistreatment in urban India : A community based study. J Elder Abuse Negl. 2005;17(2):45-61. https://doi.org/10.1300/J084v17n02_ 03.
58. Naughton C, Drennan J, Lyons I, Lafferty A, Treacy M, Phelan A, et al. Elder abuse and neglect in Ireland : results from a national prevalence survey. Age Ageing. 2012;41(1):98-103. https://doi.org/10.1093/ageing/afr107.

59. Acierno R, Hernandez MA, Amstadter AB, Resnick HS, Steve K, Muzzy W, et al. Prevalence and correlates of emotional, physical, sexual and financial abuse and potential neglect in the United States: The national elder mistreatment study. Am J Public Health. 2010;100(2):292-7. https://doi.org/1 0.2105/AJPH.2009.163089.

60. INPEA \& WHO. M i s s i n g $V$ o i c e s: Views of older persons on elder abuse. 2002.

61. Keskinoglu P, Pýcakcýefe M, Bilgic N, Giray H, Karakus N, Ucku R. Elder abuse and neglect in two different socioeconomic districts in Izmir, Turkey. Int Psychogeriatr. 2007;19(4):719-31. https://doi.org/10.1017/\$104161020700531 5.

62. White H. Elder abuse in tribal communities. In: Southwest Center for Law and Policy \& office on violence against women: U.S. Department of Justice; 2004. p. $1-8$.

63. UNFPA. Report on the status of elderly in selected states of India: Building a knowledge base on ageing in India. New Delhi, India; 2012.

64. Alexandra Hernandez-Tejada M, Amstadter A, Muzzy W, Acierno R. The National Elder Mistreatment Study: race and ethnicity findings. J Elder Abuse Negl. 2013:25:281-93.

\section{Publisher's Note}

Springer Nature remains neutral with regard to jurisdictional claims in published maps and institutional affiliations.
Ready to submit your research? Choose BMC and benefit from:

- fast, convenient online submission

- thorough peer review by experienced researchers in your field

- rapid publication on acceptance

- support for research data, including large and complex data types

- gold Open Access which fosters wider collaboration and increased citations

- maximum visibility for your research: over $100 \mathrm{M}$ website views per year

At $\mathrm{BMC}$, research is always in progress.

Learn more biomedcentral.com/submissions 